\title{
Frozen grief at the front lines of the pandemic
}

\author{
Cite as: CMAJ 2021 February 8;193:E223-4. doi: 10.1503/cmaj.1095918
}

Posted on cmajnews.com on January 21, 2021

W ith most Canadians dying in hospitals, health care workers are often present at the last moments of life and first moments of grief. But pandemic precautions and the sheer scale of loss this past year have complicated how doctors and nurses cope with their own grief on the job.

"It's infinitely more challenging to support the human elements of care because of all the barriers that COVID19 presents," says Dr. Jonathan Ailon, a general internist and palliative care physician based in Toronto.

Before the pandemic, palliative care nurses could touch and comfort most patients without layers of protective equipment or fear of exposure to a deadly disease. Palliative care doctors knew their patients more intimately and could prepare their families in person for the intense emotional journey leading up to death. Palliative care centres were open and unrestricted, allowing visitors to sleep at their loved one's bedsides and come and go as they pleased.

The pandemic changed all that.

Infection control measures have hampered relationships between health care providers, patients and patients' families. Many end-of-life conversations that previously happened in person are happening by phone, where it's impossible to tell how families are processing the information, Ailon says. Even in person, things like a comforting touch are out of the question. In previous years, Ailon would know his patients well; now, he says it's hard to learn much about them.

Not knowing patients, especially those with COVID-19 who may deteriorate and die quickly, makes it difficult for health care workers to grieve properly. "A big part of [processing] a patient's death is

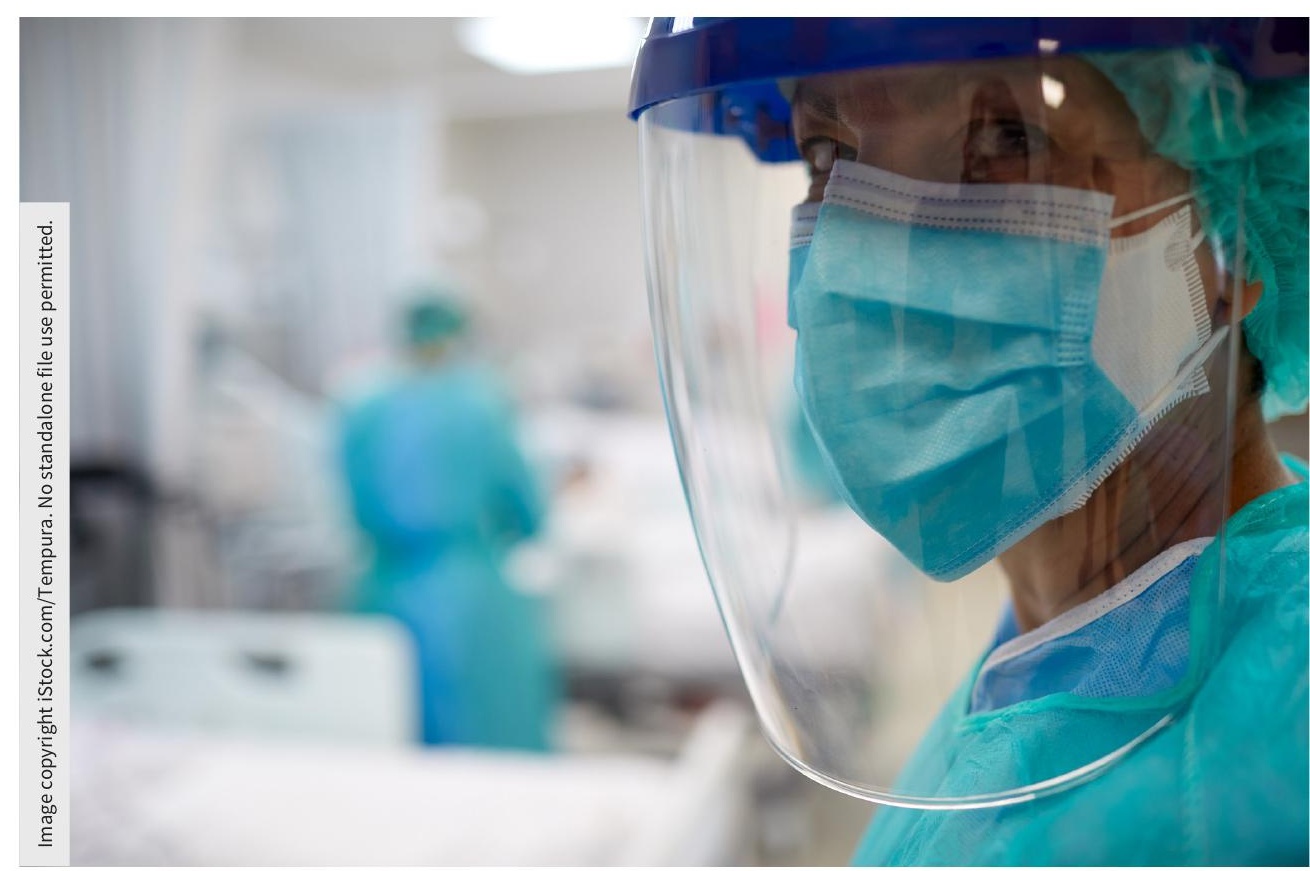

Pandemic precautions are disrupting the ways doctors and nurses cope with the deaths of patients.

understanding what is important to that individual, but also what the patient means to those around them," Ailon explains. "Because we're unable to engage with their family in the same way, there are people who pass away under my care who I feel like I don't really know."

Health care workers are trying to be empathic under very difficult circumstances, Ailon says. But the reality of practising under pandemic restrictions means "we're positioned more to care for illnesses than people."

The situation has been especially challenging in long-term care homes, where failures in the pandemic response contributed to high rates of infection and death.

At one Ontario long-term care home, 69 residents died over the span of several weeks in April and early May.
"It was extremely hard," says Evelyn*, a registered nurse at the facility who has requested anonymity to protect her job. "There was no process for grieving. I think the closest you're going to get to grieving is when you're fighting for them to live, and you're encouraging them to live. But once you get to the end where they're gone... there's no grieving process for us because it's not just one or two deaths. There are three, four, five other people [dying]."

Understaffing added moral distress to Evelyn's grief. She and most of her colleagues tested positive or fell ill during the outbreak. At one point, there were not enough staff to properly feed residents or administer medication. "I would pick the most important medication and give it to them so I could move onto the next unit because there weren't enough nurses," Evelyn says. 
At another Ontario long-term care home, 36 staff and all but three residents tested positive for severe acute respiratory syndrome coronavirus 2 last year. Emma*, a registered nurse at the home who requested anonymity, says it was "lucky in a twisted way" that only 10 people died.

"As soon as it got into our facility, it ran like wildfire. It was horrific," she says. The hardest thing to process "is that so much of it was preventable."

Emma says her facility didn't follow proper infection control practices, and people were distancing at maybe two feet, "if that."

Sick residents stayed in the same rooms with healthy residents, communal areas like the dining room stayed open, and staff members who tested positive for the virus were still working because the home was so understaffed.

Emma says her grief over the residents who died took a backseat to her worry about who would be next.

"Every single resident was critically ill, and you're not only trying to deal with the people that have passed away, but you're terrified whether everybody else can survive it," she explains. "It was constantly being on edge and not knowing who was going to be the next to go."
Ailon says human connection makes coping with the deaths of patients "harder but easier in a sense." He feels most deeply affected in situations when patients die alone or their families arrive only shortly beforehand.

Despite pandemic pressures, Ailon makes a conscious effort to ask his patients' families to tell him about the person he is caring for.

"It makes it easier for me to feel a human connection to them, and in that sense, their loss is harder [to cope with], but I also feel the care that was provided was personal and impactful. That makes the care interaction more sustainable for me," he explains.

Ailon has also taken up cycling to carve out time to process his thoughts. Outside of work, he turns off his phone and tries as much as possible to be in the moment with his family and "live a life that is effectively COVID-free."

Dr. Giovanna Sirianni, a Toronto-based family physician with a focused practice in palliative care, says it's important to recognize and talk about the emotional impact of patients' deaths.

"I know I struggle more with a person's death if their situation is related to mine in a personal way," she says. "Oftentimes, I feel like I need to talk to a colleague or talk to someone I trust to try and get that out."

Sirianni has also found it helpful to write sympathy cards to her patients' family members - something she hasn't had time to do during the pandemic but hopes to start again.

Writing cards "helped me reflect on my connection to the patient and then reflect back to their loved one about what made them special and what I'll remember about them," Sirianni says.

"I think that form of legacy building helps everyone. It helps the health care provider think about that experience and really honours that person, and I would hope it helped a loved one I sent it to."

\section{Diana Duong, CMAJ}

`Editor's note: Evelyn and Emma's names have been changed to protect their identities.

Content licence: This is an Open Access article distributed in accordance with the terms of the Creative Commons Attribution (CC BY-NC-ND 4.0) licence, which permits use, distribution and reproduction in any medium, provided that the original publication is properly cited, the use is noncommercial (i.e., research or educational use), and no modifications or adaptations are made. See: https://creativecommons.org/ licenses/by-nc-nd/4.0/ 